\title{
Giant Epulis of the Gum and Palate Area: A Case Report in Stomatology Department at Lomé University Teaching Hospital
}

\author{
Saliou Adam ${ }^{1,2 *}$, Haréfétéguéna Bissa ${ }^{1,2}$, Palokina Agoda ${ }^{3}$, Hamza Dolès Sama ${ }^{4}$, \\ Winga Foma ${ }^{2}$, Essobozou Plaoudézina Pegbessou ${ }^{5}$, Bathokédéou Amana ${ }^{6}$, \\ Essoham Boko5, Eyawèlohn Kpemissi²
}

\author{
${ }^{1}$ Department of Stomatology and Maxillofacialsurgery, Sylvanus Olympio University Teaching Hospital of Lomé, Lomé, Togo \\ ${ }^{2}$ Department of ENT, Sylvanus Olympio University Teaching Hospital of Lomé, Lomé, Togo \\ ${ }^{3}$ Department of Stomatology, Campus University Teaching Hospital of Lomé, Lomé, Togo \\ ${ }^{4}$ Department of Anesthesia and Intensive Care, Sylvanus Olympio University Teaching Hospital of Lomé, Lomé, Togo \\ ${ }^{5}$ Department of ENT, Campus University Teaching Hospital of Lomé, Lomé, Togo \\ ${ }^{6}$ Department of ENT, Regional Hospital of Lomé, Lomé, Togo \\ Email: *saliou.adam1@yahoo.com
}

How to cite this paper: Adam, S., Bissa, H., Agoda, P., Sama, H.D., Foma, W., Pegbessou, E.P., Amana, B., Boko, E. and Kpemissi, E. (2019) Giant Epulis of the Gum and Palate Area: A Case Report in Stomatology Department at Lomé University Teaching Hospital. Open Journal of Stomatology, 9, 193-198.

https://doi.org/10.4236/ojst.2019.99020

Received: July 27, 2019

Accepted: September 1, 2019

Published: September 4, 2019

Copyright $\odot 2019$ by author(s) and Scientific Research Publishing Inc. This work is licensed under the Creative Commons Attribution International License (CC BY 4.0).

http://creativecommons.org/licenses/by/4.0/

\section{(c) (i) Open Access}

\begin{abstract}
Introduction: Epulis is a pseudotumor very common in women. If neglected, it can reach a considerable volume. The marginal gingiva is very involved in the tumor either in isolation or with periodontal and alveolar bone. The epulis sits classically on the vestibular gum, rarely on the palatal side. We report a case of palatal giant epulis which posed a diagnostic problem. Case report: This was a 50-year-old patient with a large tumor occupying the entire oral cavity and pushing all nearby organs. This lesion had been evolving for ten years, with a tendency to gradually increase of its volume. The orthopantomogram revealed the destruction of the underlying alveolar bone without signs of tumor invasion. Surgical excision was performed, removing all the tumor in the vicinity of the nasopalatine vascular pedicle. The pathological examination concludes with an inflammatory epulis. Conclusion: The epulis is a benign tumor of the gum, circumscribed, localized preferentially at the neck of one or two contiguous teeth. It occurs more in women, with a predilection for the vestibular side, rarely the palatal side. In the absence of appropriate treatment it can lead to a large tumor, posing a diagnostic problem and causing functional or aesthetic discomfort. Complete surgical excision with histological examination remains the solution. Healing without sequelae is the rule.
\end{abstract}

\section{Keywords}

Giant Epulis, Surgical Excision, Stomatology, Lome 


\section{Introduction}

The epulis is described as a benign hyperplastic tumor-like of the gingival or juvenile mucosa. It is thought to be secondary to inflammatory reactions responding to an iterative irritative phenomenon. In fact, this lesion often sits in the vicinity of a dental or prosthetic irritating spine (supernumerary tooth, ectopic tooth, poorly adapted prosthesis). Sometimes there is a notion of poor oral hygiene (tartaric gingivitis). If the inflammatory cause is irrefutable, some authors suggest the involvement of the host factor. Thus it has been described the development of epulis in women in the genital activity and in pregnant women because of the influence of hormonal disorders [1] [2]. In addition, other factors favoring the genesis of these conditions have been described such as anemias, hemostasis disorders and parasitic eosinophilias [3]. The epulis is a rounded or oval tumor with regular or multi-lobed surface. It can be sessile or pedunculated, with elastic consistency and vinous red color. It usually sits on the vestibular slope of the second and third teeth area, more rarely in the palatal region. Its diagnosis of certainty is histological and distinguishes among others inflammatory epulis, hemangiomatous, fibrous, fibro-inflammatory, fibroblastic, giant cell, and osteoid [4]. Epulis is a very common pathology, especially in women, which, if neglected, can reach a considerable volume. We report a case of palatal giant epulis which posed a diagnostic problem because of its location and its volume.

\section{Case Report}

It was a 50-year-old patient who was received at stomatological consultation for a large tumor occupying the entire oral cavity. This lesion evolved for ten years without any notion of pain, but with a tendency to gradually increase of its volume. The patient told have been consulted several traditional healers who gave her infusions without success on the tumor. It was after a TV-show about the management of this type of lesion in a specialized hospital that her daughter asked her to consult stomatology department of Sylvanus Olympio University Teaching Hospital for better care. The interrogation found no personal or family pathological antecedent. The patient complained of difficulty eating properly and the impossibility of closing her mouth. The general clinical examination noted a conservation of his general condition and a good coloring of the integuments. The extra oral or facial examination revealed a deformation of the face on the right side and a labial incompetence due to the externalization of the tumor. There were neither cervical lymphadenopathies nor mandibular ones. The endo-oral examination showed a voluminous oval mass, multilobal, red, with elastic consistency (Figure 1). That tumor was not very painful, but was bleeding easily on contact, and mobile, respecting the palate. Its pedicle was not visible. The tumor occupied the entire oral cavity, pushing the tongue and deforming the dental arcade of the first sector (Figure 2). The teeth 13,16, 17, 18 were very mobile; teeth 14 and 15 were absent, and there was diffuse tartaric gingivitis on the rest of the dentition. The Orthopantomogram performed showed an alveolysis on all the first dentalsector, without signs of tumor invasion. 


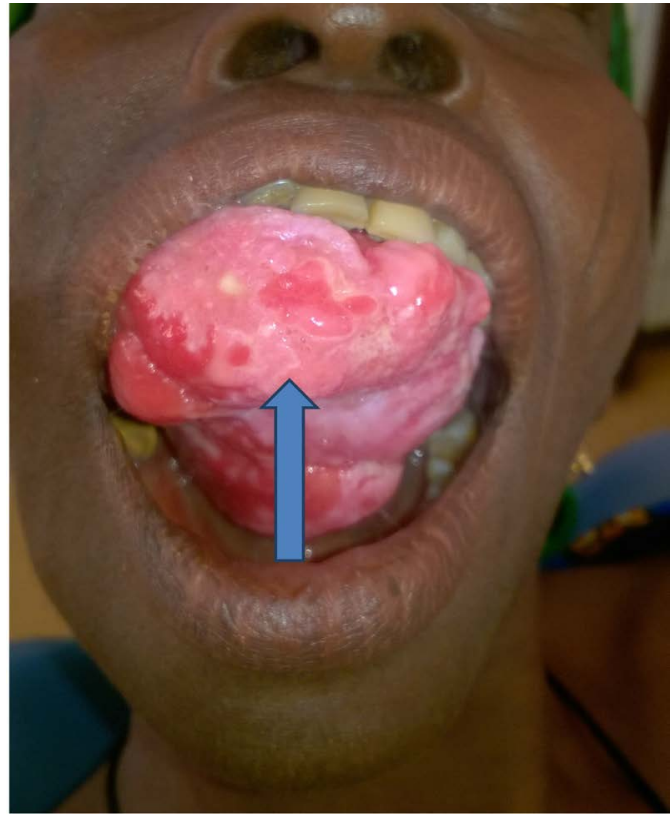

Figure 1. Giant epulis occuping the entire oral cavity, pushing the tongue.

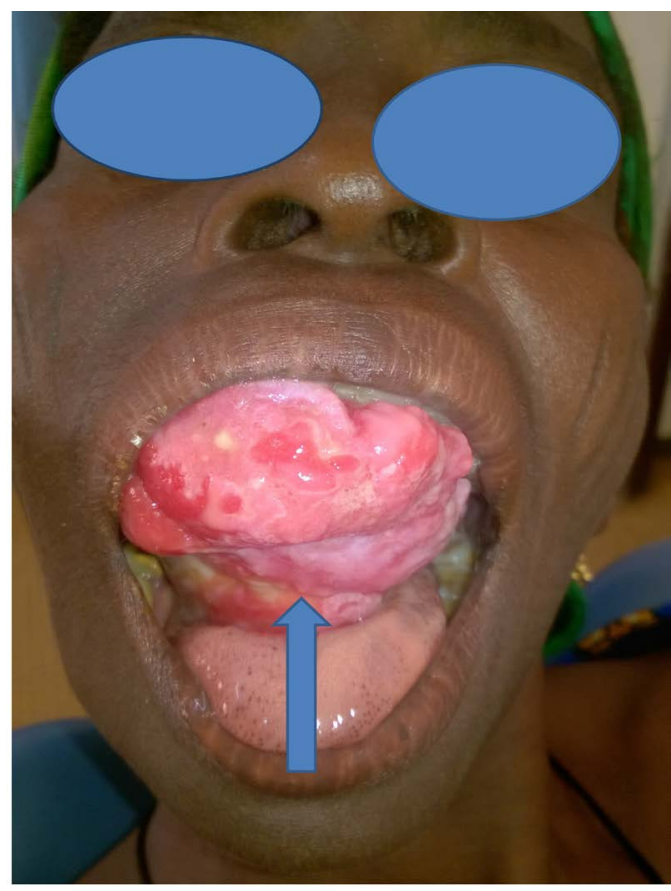

Figure 2. The tumor pushing the tongue.

Surgical excision was performed under general anesthesia, removing all the tumor that had a pedicle in the vicinity of the nasopalatine vascular pedicle. It measured $9 \mathrm{~cm} \times 6 \mathrm{~cm} \times 4 \mathrm{~cm}$ (Figure 3(a), Figure 3(b)). Haemostasis was controlled by electrocautery and recovering Surgiceltissue on the operative site. The pathological examination concludes with an inflammatory epulis (Figure 4). The immediate operative follow-up was simple under level 2 analgesics 


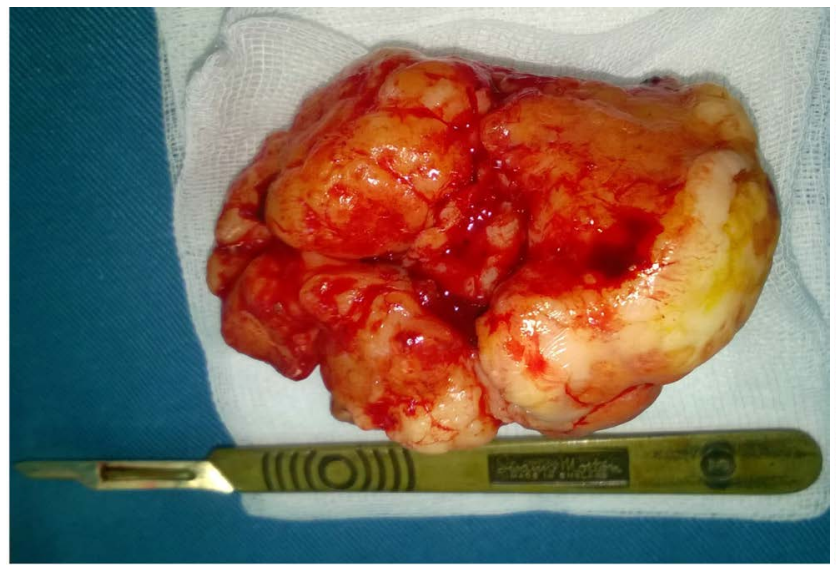

(a)

Figure 3. (a) \& (b) Epulis after surgical excision.

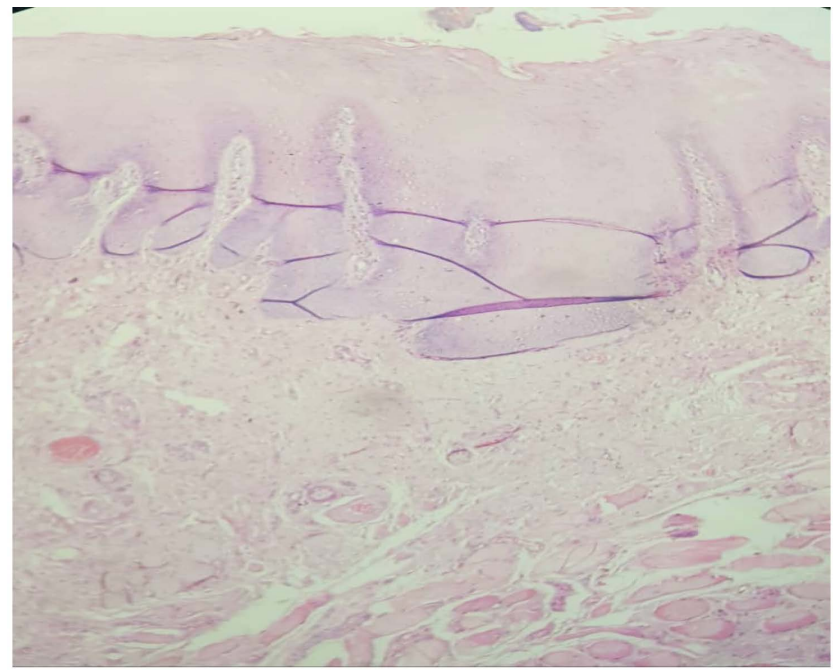

(a)

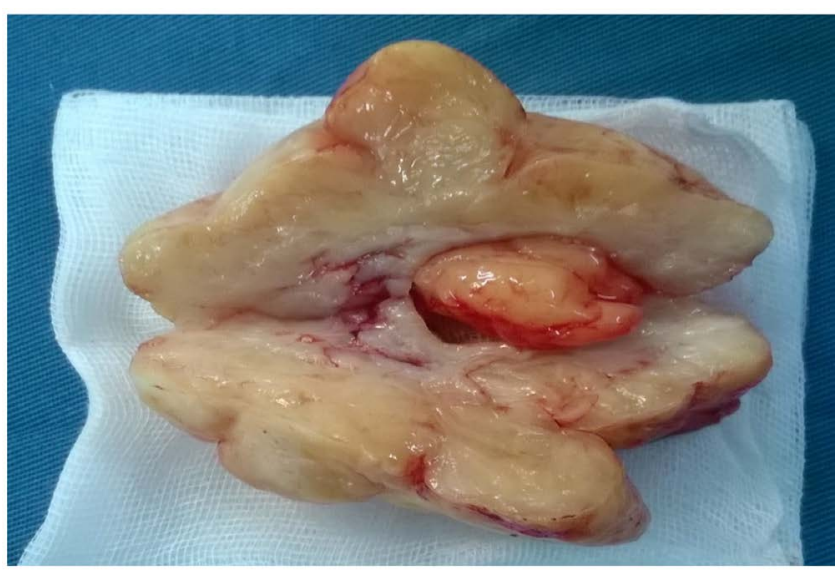

(b)

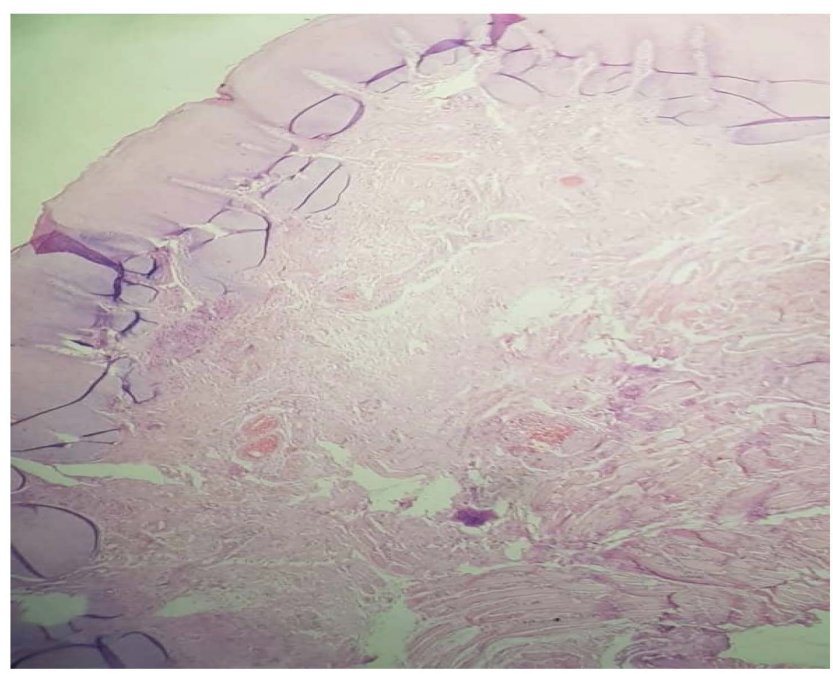

(b)

Figure 4. (a) Pathological examination showing inflammatory epulis $\times 40$; (b) Pathological examination showing inflammatory epulis $\times 100$.

(tramadol-Paracetamol hydrochloride), antibiotic (Amoxicillin-clavulanic acid) and local antiseptic baths (Polyvidone iodine). The patient recovered her normal mouth's function without sequelae (Figure 5). Secondly, the patient underwent complete descaling, extraction of tooth 13 and prosthetic rehabilitation of the edentulous area.

\section{Discussion}

The epulis is a benign tumor of the gum that reaches the woman more often than the man [5]. The most etiologies in its occurrence are the inflammatory causes, with in particular a local frequently mechanical irritation or infectious ones. Predisposing factors such as hormonal factors are also incriminated in women [1]. All these conditions are consistent with our observation where it is 


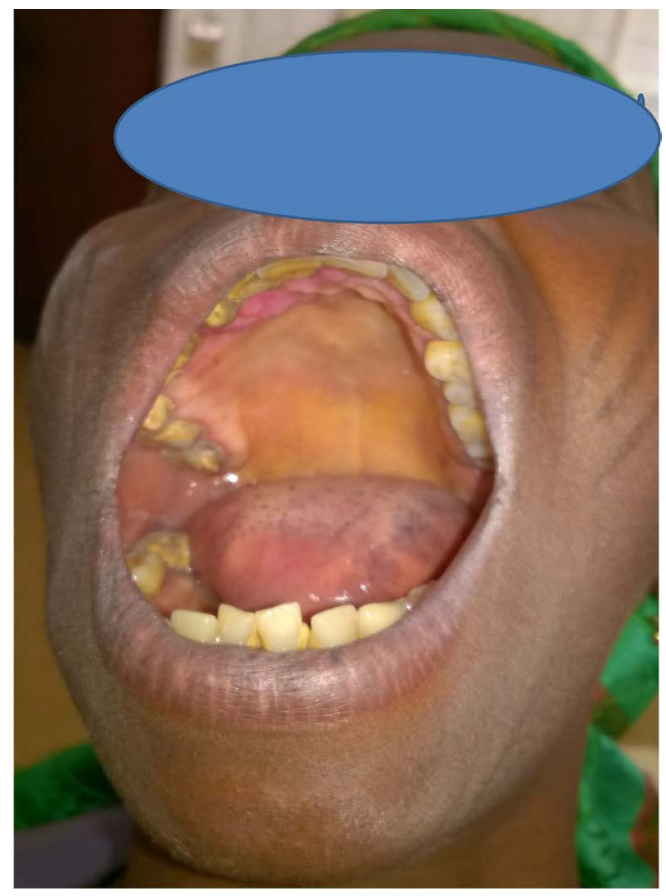

Figure 5. The patient three mounths after surgical excision.

indeed a woman, with an almost asymptomatic lesion, well defined. In her case the most plausible cause seems to be poor oral hygiene, including tartaric gingivitis. The epulis is localized preferentially on the vestibular slope of the second and third teeth, and often has the size of a hazelnut [6]. In the absence of appropriate treatment it can lead to a large tumor, causing functional or aesthetic discomfort [6] and may pose a diagnostic problem. In our patient, homelessness among traditional healers, ignorance of the disease and its contributing factors explain the delay in diagnosis [7], with a monstrous increase in the volume of the tumor and its corollaries the functional and aesthetic discomfort that she reported. This large volume of the tumor and its unusual location on the palatal side almost led us astray in the diagnostic process and make us think of a malignant tumor such as squamous cell carcinoma of the palate or tongue. But the slowness of evolution, the absence of symptoms such as pain, the mobility of the tumor, the absence of satellite lymphadenopathies, made us retain the hypothesis of epulis. We have not found in the literature a description of the same tumor on palatal side. This notion made our case very original. The surgical excision was performed under general anesthesia in our patient to control better the intraoperative hemostasis. Two reasons explained our decision: the pedicle was not clinically accessible, and the comfort of the patient will be better under general anesthesia. Indeed, the surgical treatment of the epulis is conventionally done under local anesthesia with the electrocautery or CO2 laser or Nydium-Yag laser [8], in order to minimize the cost of hospitalization. Other treatments are proposed such as ligation for pediculated lesions, or cryotherapy with liquid nitrogen at $-196^{\circ} \mathrm{C}$. The histology of the operative specimen found an inflamma- 
tory epulis. The epulis has a good prognosis if the excision is complete [9]. The histological type of the epulis does not be a condition to the prognosis of this benign lesion.

\section{Conclusion}

The diagnosis of the epulis is generally easy regarding the clinical aspect evocative of this lesion. However, it must be confirmed by the histology of the operative specimen, and the sole pledge to differentiate it from other malignant deceptive tumors of the oral cavity. Treatment of the epulis is surgical, and can be performed under local anesthesia and sometimes general anesthesia. Ignorance, inaccessibility to modern care, and sometimes homelessness among traditional healers are all factors that delay the diagnosis and codified management, with corollaries bulky tumors with functional and aesthetic consequences.

\section{Consent}

We obtained the consent of the patient for publishing her pictures.

\section{Conflicts of Interest}

The authors declare no conflicts of interest regarding the publication of this paper.

\section{References}

[1] Akazane, A. and Badredine, H. (2014) Epulis à propos d'un cas. The Pan African Medical Journal, 17, 19. https://doi.org/10.11604/pamj.2014.17.19.2997

[2] Adam, S., Sama, H.D., Agoda, P., Bissa, H., Foma, W., Pegbessou, E.P., Amana, B., Boko, E. and Kpemissi, E. (2019) Epidemiological, Clinical and Therapeutic Issues of Epulis at Campus University Teaching Hospital of Lomé: About 33 Cases. Open Journal of Stomatology, 9, 168-174. https://doi.org/10.4236/ojst.2019.97017

[3] Rakotoarivony, A.E. (2013) Prise en charge d'une épulis récidivante et revue de la littérature. Revue D'Odonto-Stomatologie, 6, 9-15.

[4] Choudhari, P., Kamble, P. and Jadhav, A. (2013) Gingival Epulis: Report of Two Cases. IOSR Journal of Dental and Medical Sciences, 7, 40-44. https://doi.org/10.9790/0853-0734044

[5] Rafael, S.S. and Mariano, T.R. (2005) Hiperplasiaepithelial Focal. Medicina Oral, Patología Oral y Cirugía Bucal, 10.

[6] Adouko-Aka, J.A., Assouan, C., N'guessan, D., Abouna, A.-D., YapoAngoh, J.-J., Konan, E. and Assa, A. (2015) Epulis géante ulcérée: Un cas. Médecine Buccale Chirurgie Buccale, 21, 225-227.

[7] Messanga, C.B., Onana, J., Sando, Z., Ebolo, X. and Bengono, G. (2006) Epulis géante pédiculée: A propos d'un cas. Médecine Buccale Chirurgie Buccale, 12, 159-62.

[8] Benaazad, D., Cherkaoui, A., Elmoussadden, M. and Elmohtarim, B. (2009) Le laser en parodontie. Actualités Odonto-Stomatologiques, 247, 217-229.

[9] Traore, H., Kamissoko, K., Traore, D., Coulibali, A.D., Théra, T.D. and Touré, K. (2013) Epulis Fibreuse Remaniée: Prise en charge chirurgicale d'un cas. Mali Medical, $53,45-48$. 